\title{
Study on compatibility optimization of resin-based permeable pavement bricks
}

\author{
Menghao Luo ${ }^{1}$, Xiong Zhang ${ }^{1, *}$, Heng Zhang ${ }^{2}$, Xiaofu Wang ${ }^{1}$, and Rongrong $\mathrm{Du}^{1}$ \\ ${ }^{1}$ Key Laboratory of Advanced Civil Engineering Materials of Ministry of Education, Tongji University, Shanghai, China \\ ${ }^{2} \mathrm{CCCC}$ (Shanghai) Harbor Engineering Design and Research Institute Co., Ltd, Shanghai, China
}

\begin{abstract}
The permeable pavement plays an important role in mitigating urban flooding. In order to explore the relationship between materials and properties to better guide the practical production of resin-based permeable bricks, 10 kinds of representative aggregate samples with obvious different characteristics were selected for preparation. In this study, Image Pro Plus was used to binarize the acquired image pictures of the aggregate so as to obtain particle group characteristic parameters. The properties and porosity of the brick were measured in order to describe the influence of the material. The results are as follows. The relative standard deviation of aggregate and the amount of cementing material are negatively related to the compressive strength of permeable bricks, but positively related to water permeability and filtration performance. The roundness and roughness of the aggregate are the opposite. Furthermore, the porosity of the permeable brick is the essential reason for this phenomenon, that is, as the porosity increase, the compressive strength decrease, but the water permeability and the filtration performance become better. In the end, an optimization method for the compatibility of resin-based pavement permeable bricks was proposed through reflecting all factors in a two-bit flat grayscale image which can be applied in performance prediction and guidance of material selection.
\end{abstract}

\section{Introduction}

The Sponge City Project plays an important role in alleviating "urban heat island effect", saving water and improving the ecological environment ${ }^{[1]}$. In the process of sponge city construction, permeable pavement as an important construction facility has become an important part of the sponge city construction process ${ }^{[1,2]}$. Due to the high strength, good permeability and long-term effectiveness of resin-based permeable bricks, it has caused extensive research by scholars ${ }^{[3]}$.

Wang Pingping ${ }^{[4]}$ et al. used epoxy resin GCC135 and curing agent $\mathrm{GCC} 137$ to bond aeolian sand to produce a permeable brick with a compressive strength of $41.1 \mathrm{MPa}$ and a water permeability coefficient of $2.1 \times 10^{-2} \mathrm{~cm} / \mathrm{s}$; Zhang Weimin ${ }^{[5]}$ used the cemented material with aeolian sand as aggregate to develop a permeable brick with a compressive strength of up to $82.3 \mathrm{MPa}$ and a water permeability coefficient of more than $2.0 \times 10^{-2} \mathrm{~cm} / \mathrm{s}$. However, neither of them has conducted in-depth research on the relationship between aggregate particle group parameters and permeable brick performance. KayWille ${ }^{[6]}$ et al. used the recommended equations involving matrix strength, total porosity, aggregate size and average pore size to predict the compressive strength of permeable materials. However, the study did not comprehensively consider the relationship between raw material parameters and various properties of permeable materials. The performance of resin-based permeable pavement bricks is excellent, but the long-term effectiveness of resin-based permeable bricks and the compatibility optimization of raw materials need to be studied, which restricts its application in actual production.

Based on this, on the basis of exploring the relationship between aggregate particle parameters and the amount of cementing material and the performance of resin-based permeable bricks, this paper discusses its internal influence mechanism, and considers the optimization relationship between the aggregate and cementing material, which can guiding the preparation of resin-based permeable pavement bricks with excellent performance.

\section{Materials and Methods}

\subsection{Materials}

\subsubsection{Aggregate}

In this paper, 10 kinds of representative aggregate samples with obvious different characteristics (particle size, RD, $\mathrm{RG}$, etc.) were selected. The particle gradation of them is shown in Fig.3.

\subsubsection{Resin}

AB-1 type epoxy resin (two-component), its component $\mathrm{A}$ is bisphenol A epoxy resin, component $\mathrm{B}$ is amine curing agent 593. The epoxy is cured in a dry environment at room temperature, and the $1 \mathrm{~d}$ strength can reach $90 \%$ of

* Corresponding author: xiong.zhang@ vip.sina.com 
the maximum value. The performance is shown in Table 1 .

\begin{tabular}{ccccc}
\multicolumn{5}{c}{ Table 1 Properties of AB-1 epoxy resin } \\
\hline Viscosity & Compressiv & Tensile & Bond & Elongation/ \\
$\left(20^{\circ} \mathrm{C}\right) /(\mathrm{mPa} \cdot \mathrm{s})$ & $\mathrm{e}$ & strength/MPa & $\begin{array}{c}\text { strength/MP } \\
\text { atrength/M }\end{array}$ & \\
& $\mathrm{Pa}$ & & & \\
\hline $60-100$ & $\geq 35$ & $>15$ & $>3.0$ & 8 \\
\hline
\end{tabular}

\subsubsection{Kaolin powder}

The kaolin powder was used to prepare simulated flow path materials for water filtration performance test, the gradation requirements are shown in Table 2.

\begin{tabular}{cc} 
Table 2 Gradation of Kaolin powder \\
\hline Particle size/mesh & Mass ratio/\% \\
\hline $200 \sim 400$ & 25 \\
$140 \sim 200$ & 20 \\
$100 \sim 140$ & 25 \\
$70 \sim 100$ & 25 \\
$40 \sim 70$ & 5 \\
\hline
\end{tabular}

\subsection{Sample preparation}

According to the formula, weigh the aggregate and resin in the mortar mixer, mix it evenly, pour it into the mold and place it in the press at $2.5 \mathrm{MPa}$ for $90 \mathrm{~s}$. The molding size is $160.0 \mathrm{~mm} \times 132.0 \mathrm{~mm} \times 17.3 \mathrm{~mm}$ for permeable test and $40.0 \mathrm{~mm} \times 40.0 \mathrm{~mm} \times 160.0 \mathrm{~mm}$ for strength test, it can be removed after 24 hours of natural curing to obtain a sample of permeable pavement brick.

\subsection{Test method}

\subsubsection{Particle group characteristic parameters}

This article uses an optical stereo microscope and a Sony ILCE-60002430 million pixel camera to acquire images of 10 kinds of aggregates (respectively marked as S1 to S10). The results are shown in Fig.1.
Image Pro Plus is used to binarize the acquired image pictures to extract the sand grain contour and convert the microscope image into a black and white binary image ${ }^{[7,8]}$, as shown in Fig.2. After the image is measured by the software, the required parameter value is obtained.
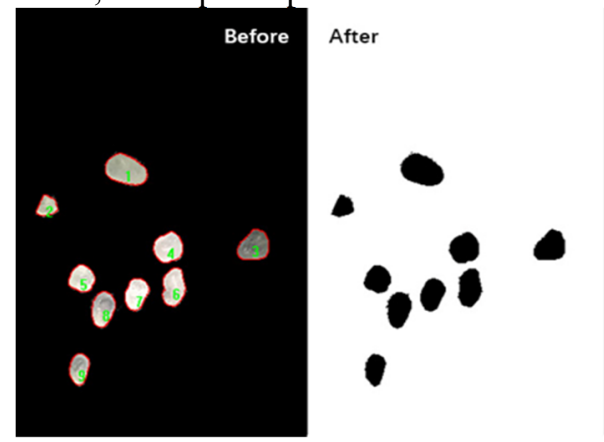

Fig.2 Microscope image \& black and white binary image

\subsubsection{Test method for water permeability}

According to the standard of "Permeable Pavement Bricks and Permeable Road Panels" (GB/T25993-2010) [9], a water permeability coefficient tester is made to test the water permeability of test blocks with a size of $160.0 \mathrm{~mm} \times 132.0 \mathrm{~mm} \times 17.3 \mathrm{~mm}$.

\subsubsection{Test method for water filtration performance}

According to the standard of "Sand-based Permeable Brick" (JG/T376-2012) ${ }^{[10]}$, Kaolin powder and deionized water are used to prepare a standard simulated road path flow sample for water filtration performance test.

\subsubsection{Test method for compressive strength}

According to the standard of "Sand-based Permeable Brick" (JG/T376-2012) ${ }^{[10]}$, an electro-hydraulic pressure testing machine is used to conduct strength test on the test block with a size of $40.0 \mathrm{~mm} \times 40.0 \mathrm{~mm} \times 160.0 \mathrm{~mm}$.

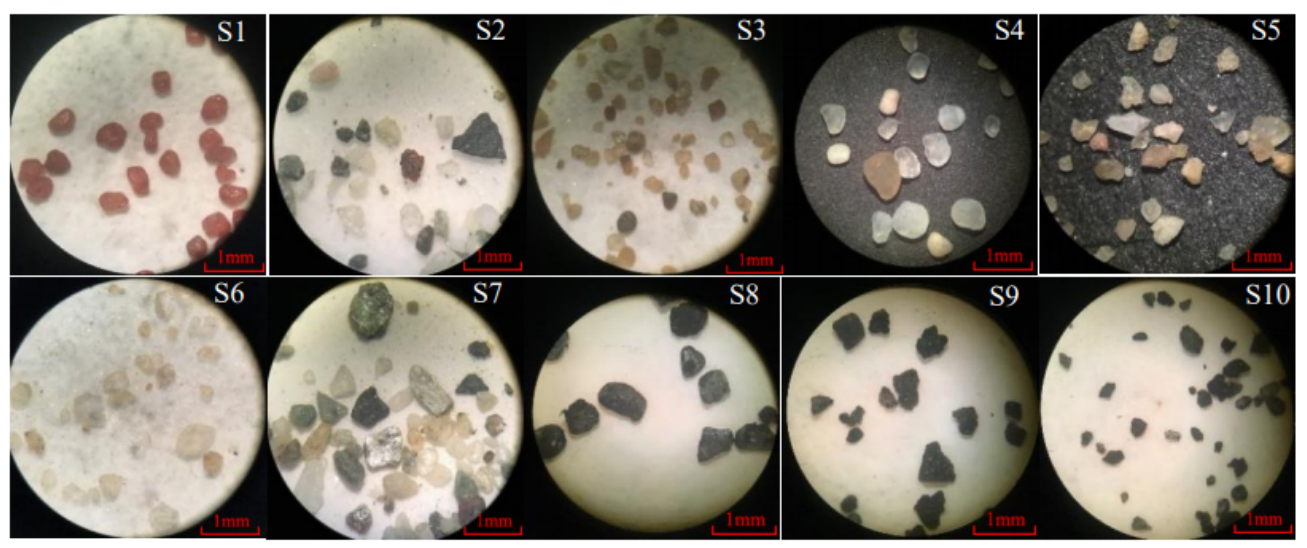

Fig.1 Photograph of 10 aggregate samples taken with a microscope lens 


\subsubsection{Porosity test method}

Putting the test block soaked in water for $48 \mathrm{~h}$ and then take it out. Wiping off the water attached to the surface and weigh it immediately to obtain the mass of the test block after absorbing water for $48 \mathrm{~h}\left(\mathrm{~m}_{12}\right)$. Then put the test block in an oven at $60 \pm 5^{\circ} \mathrm{C}$ to dry it, and weigh it once every $24 \mathrm{~h}$ until the difference between the continuous weighing values is less than $0.1 \%$, which is regarded as the quality of the dry test block $\left(\mathrm{m}_{22}\right)$. Measure the size of the test block, calculate the volume of the test block, and calculate the porosity of the test block according to formula (1)

$$
K=\frac{m_{12}-m_{22}}{V \cdot \rho_{w}} \cdot 100 \%
$$

\section{Results and discussion}

\subsection{Effect of aggregate particle group parameters on the properties of resin-based permeable bricks}

The test used 10 kinds of aggregates (S1-S10), and the resin-based permeable brick was prepared under the dosage of $4.5 \%$ epoxy resin, and their compressive strength (R), water permeability coefficient $(\mathrm{V})$ and water filtration frequency (n) was measured. Three preferred aggregate particle characteristic parameters: relative standard deviation $(\alpha)$, roundness $\left(\mathrm{R}_{\mathrm{D}}\right)$ and roughness $\left(\mathrm{R}_{\mathrm{G}}\right)$ were used to discuss the macrophysics of aggregate gradation, shape and surface structure.

\subsubsection{Influence of Aggregate Gradation on Properties of Resin-based Permeable Brick}

The sieve residue of 10 kinds of aggregates obtained by the vibration sieve test is shown in Fig. 3.

It can be seen from Fig.3, the gradation of 10 kinds of aggregates is mainly concentrated above $0.4 \mathrm{~mm}$, and the distribution is different, but the frequency distribution of the number of particles is basically close to the modified Gaussian distribution. The modified normal distribution density function is expressed as:

$$
\mathrm{y}=y_{0}+\frac{A}{w \sqrt{\pi / 2}} e^{-2 \frac{\left(\frac{\left(x-x_{c}\right)^{2}}{w^{2}}\right.}{2}}
$$

$x_{c}$-the most likely particle size,

$w$-the standard deviation of the distribution.

In addition, the relative standard deviation of the distribution is calculated by the formula as follows:

$$
\alpha \equiv \frac{w}{x_{c}}
$$

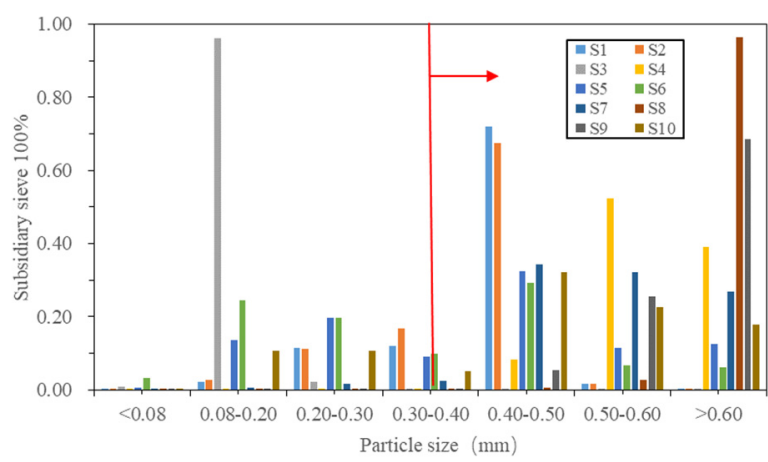

Fig.3 The sieving surplus of 10 kinds of aggregates

Using the modified Gaussian distribution to fit the particle size of 10 kinds of aggregate samples to indicate their particle size distribution, and then calculate the value of the relative standard deviation through formulas (2) and (3) to characterize the distribution of the particle group.

Table 3 shows the fitting parameters of the gradation normal distribution of the 10 aggregates obtained by the fitting calculation.

Figure 4 shows the relationship between the relative standard deviation of aggregate and the performance of permeable bricks.

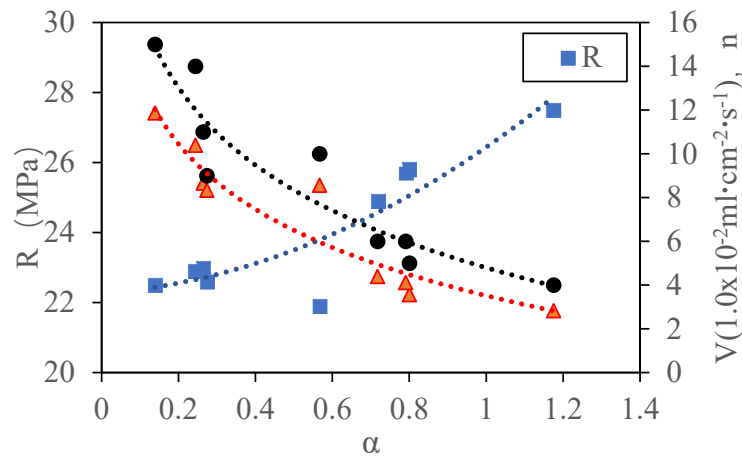

Fig.4 Relationship between aggregate relative standard deviation and permeable brick performance

The characteristic parameters of the aggregate can affect the thickness of the resin layer and the number of cured joints, thereby affecting its properties ${ }^{[11]}$. Therefore, the greater the relative standard deviation of the aggregate, the lower the porosity, the greater the number of curing contact, resulting in the higher strength of the permeable brick, but the permeability and water filtration performance is lower under the same type and amount of epoxy resin, which are shown in Fig.4.

Table 3 Fitting parameters of normal distribution of gradation of 10 kinds of aggregates

\begin{tabular}{ccccccccccc}
\hline Number & $\mathrm{S}_{1}$ & $\mathrm{~S}_{2}$ & $\mathrm{~S}_{3}$ & $\mathrm{~S}_{4}$ & $\mathrm{~S}_{5}$ & $\mathrm{~S}_{6}$ & $\mathrm{~S}_{7}$ & $\mathrm{~S}_{8}$ & $\mathrm{~S}_{9}$ & $\mathrm{~S}_{10}$ \\
\hline$w$ & 0.066 & 0.0735 & 0.1329 & 0.2746 & 0.2419 & 0.131 & 0.2098 & 0.0697 & 0.1042 & 0.0823 \\
$x_{c}$ & 0.25 & 0.2686 & 0.1661 & 0.4844 & 0.3059 & 0.1826 & 0.1785 & 0.5026 & 0.4273 & 0.3616 \\
$\alpha$ & 0.264 & 0.2736 & 0.8001 & 0.5668 & 0.7907 & 0.7174 & 1.1753 & 0.1386 & 0.2438 & 0.2276 \\
\hline
\end{tabular}


3.1.2 Effect of aggregate shape and surface structure on the properties of resin-based permeable brick

With reference to the research on the morphological characteristics of coarse aggregates by Li Xiaoyan ${ }^{[12]}$ et al, the $R_{D}$ and $R_{G}$ were selected to characterize the particle shape and surface structure of the resin-based permeable brick aggregate. The data of $\mathrm{R}_{\mathrm{D}}$ and $\mathrm{R}_{\mathrm{G}}$ obtained by image analysis is shown in Table 4 and Table 5.

This paper calculates the average $\mathrm{R}_{\mathrm{D}}$ and $\mathrm{R}_{\mathrm{G}}$ according to the particle weight of each particle size in each aggregate sample, and uses the gray correlation analysis method to analyze the correlation between the parent sequence of ten aggregates (macroscopic performance index of resin-based permeable pavement bricks) and the child sequence $\left(R_{D}\right.$ and $R_{G}$ of aggregates) is obtained. Table 6 shows the gray correlation calculation results.

Table 6 Gray correlation calculation of 10 kinds of aggregates

\begin{tabular}{|c|c|c|c|c|c|c|}
\hline \multicolumn{2}{|c|}{ Number } & S1 & $\mathrm{S} 2$ & S3 & S4 & S5 \\
\hline \multirow{3}{*}{$\mathrm{R}_{\mathrm{D}}$} & $\mathrm{R}$ & -0.473 & -0.505 & -0.512 & -0.572 & -0.542 \\
\hline & $\mathrm{V}$ & +0.645 & +0.663 & +0.672 & +0.593 & +0.677 \\
\hline & $\mathrm{n}$ & +0.732 & +0.742 & +0.706 & +0.634 & +0.731 \\
\hline \multicolumn{2}{|c|}{ Number } & S6 & S7 & S8 & S9 & $\mathrm{S} 10$ \\
\hline \multirow{3}{*}{$\mathrm{R}_{\mathrm{D}}$} & $\mathrm{R}$ & -0.443 & -0.562 & -0.508 & -0.522 & -0.487 \\
\hline & $\mathrm{v}$ & +0.682 & +0.634 & +0.652 & +0.663 & +0.652 \\
\hline & $\mathrm{n}$ & +0.752 & +0.714 & +0.682 & +0.742 & +0.670 \\
\hline \multicolumn{2}{|c|}{ Number } & S1 & $\mathrm{S} 2$ & S3 & S4 & S5 \\
\hline \multirow{3}{*}{$\mathrm{R}_{\mathrm{G}}$} & $\mathrm{R}$ & -0.531 & -0.587 & -0.575 & -0.524 & -0.543 \\
\hline & $\mathrm{v}$ & +0.563 & +0.592 & +0.631 & +0.631 & +0.621 \\
\hline & $\mathrm{n}$ & +0.602 & +0.578 & +0.654 & +0.628 & +0.583 \\
\hline \multicolumn{2}{|c|}{ Number } & S6 & S7 & S8 & S9 & $\mathrm{S} 10$ \\
\hline \multirow{3}{*}{$\mathrm{R}_{\mathrm{G}}$} & $\mathrm{R}$ & -0.507 & -0.473 & -0.505 & -0.512 & -0.542 \\
\hline & $\mathrm{v}$ & +0.531 & +0.645 & +0.663 & +0.572 & +0.630 \\
\hline & $\mathrm{n}$ & +0.540 & +0.732 & +0.742 & +0.554 & +0.617 \\
\hline
\end{tabular}

From the results in Table 6 , it can be seen that the effects of $R_{D}$ and $R_{G}$ on resin-based permeable pavement materials are isotropic, negatively correlated with compressive strength, and positively correlated with water permeability coefficient and filtration times. That is, the rounder the aggregate shape and the rougher the surface, the more the permeable brick prepared tends to have a larger water permeability coefficient and higher water filtration performance, but the compressive strength is lower. It is speculated that the $R_{D}$ and $R_{G}$ will affect the porosity of the permeable brick, which in turn will affect the performance of the material.

\subsection{The effect of cement material on the performance of resin-based permeable brick}

The three macroscopic properties of resin-based permeable bricks with the amount of epoxy resin (EP) ranging from $4.0 \%$ to $6.0 \%$ with a gradient of $0.5 \%$ are discussed. The selected resin is modified epoxy E-44, curing agent 593, and the aggregates are S9 (A) with better permeability, S4 (B) with better comprehensive performance and S6 (C) with better strength. Fig. 5 shows the relationship between the compressive strength $(\mathrm{R})$ water permeability coefficient (V) of resin-based permeable bricks and the amount of epoxy resin (EP).

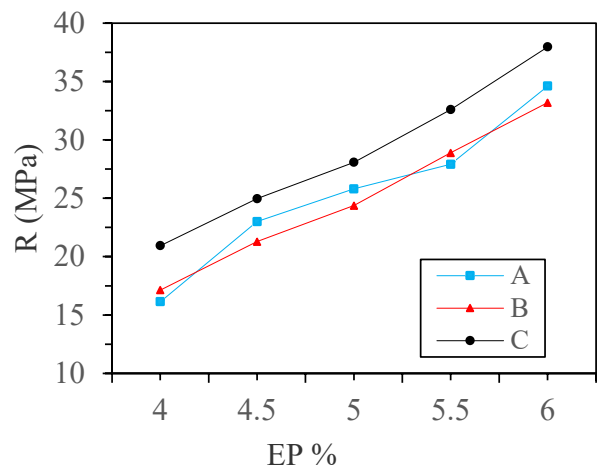

(a)

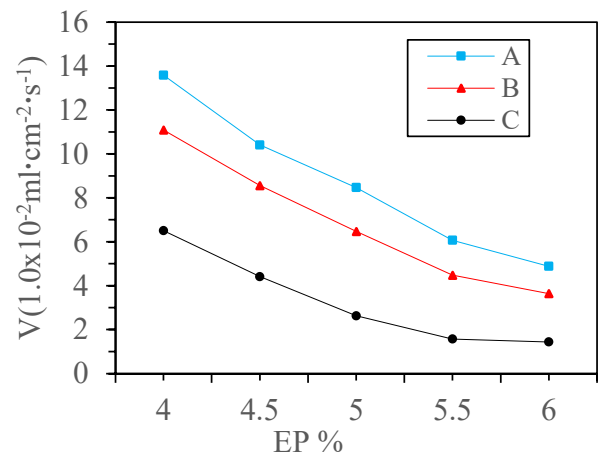

(b)

Fig.5 Relationship between EP, R and V

Table 4 Raw data of $R_{D}$ analysis of 10 kinds of aggregate sand samples

\begin{tabular}{ccccccccccc}
\hline \multirow{2}{*}{$\begin{array}{c}\text { Particle } \\
\text { size/mm }\end{array}$} & \multicolumn{10}{c}{$\mathrm{R}_{\mathrm{D}}$} \\
\cline { 2 - 10 } & $\mathrm{S} 1$ & $\mathrm{~S} 2$ & $\mathrm{~S} 3$ & $\mathrm{~S} 4$ & $\mathrm{~S} 5$ & $\mathrm{~S} 6$ & $\mathrm{~S} 7$ & $\mathrm{~S} 8$ & $\mathrm{~S} 9$ & $\mathrm{~S} 10$ \\
\hline$<0.1$ & 0.902 & 0.925 & 0.912 & 0.931 & 0.924 & 0.925 & 0.955 & 0.886 & 0.922 & 0.925 \\
$0.1-0.2$ & 0.883 & 0.950 & 0.922 & 0.911 & 0.895 & 0.926 & 0.940 & 0.872 & 0.915 & 0.930 \\
$0.2-0.3$ & 0.878 & 0.959 & 0.905 & 0.902 & 0.932 & 0.914 & 0.925 & 0.865 & 0.913 & 0.892 \\
$0.3-0.4$ & 0.896 & 0.955 & 0.901 & 0.889 & 0.866 & 0.895 & 0.905 & 0.890 & 0.899 & 0.897 \\
$0.4-0.5$ & 0.882 & 0.946 & 0.882 & 0.916 & 0.824 & 0.872 & 0.904 & 0.866 & 0.903 & 0.899 \\
$0.5-0.6$ & 0.881 & 0.920 & 0.887 & 0.921 & 0.901 & 0.830 & 0.914 & 0.879 & 0.912 & 0.912 \\
Average & 0.887 & 0.945 & 0.907 & 0.928 & 0.898 & 0.889 & 0.895 & 0.878 & 0.910 & 0.902 \\
\hline
\end{tabular}


Table $5 R_{\mathrm{G}}$ of 10 kinds of aggregate sand samples

\begin{tabular}{ccccccccccc}
\hline \multirow{2}{*}{$\begin{array}{c}\text { Particle } \\
\text { size/mm }\end{array}$} & \multicolumn{10}{c}{$\mathrm{R}_{\mathrm{G}}$} \\
\cline { 2 - 11 } & $\mathrm{S} 1$ & $\mathrm{~S} 2$ & $\mathrm{~S} 3$ & $\mathrm{~S} 4$ & $\mathrm{~S} 5$ & $\mathrm{~S} 6$ & $\mathrm{~S} 7$ & $\mathrm{~S} 8$ & $\mathrm{~S} 9$ & $\mathrm{~S} 10$ \\
\hline$<0.1$ & 1.034 & 1.012 & 1.022 & 1.013 & 1.010 & 1.016 & 1.018 & 1.066 & 1.021 & 1.034 \\
$0.1-0.2$ & 1.032 & 1.018 & 1.027 & 1.022 & 1.018 & 1.023 & 1.016 & 1.069 & 1.016 & 1.038 \\
$0.2-0.3$ & 1.040 & 1.023 & 1.033 & 1.021 & 1.024 & 1.027 & 1.015 & 1.073 & 1.013 & 1.043 \\
$0.3-0.4$ & 1.046 & 1.026 & 1.028 & 1.012 & 1.031 & 1.028 & 1.010 & 1.083 & 1.022 & 1.042 \\
$0.4-0.5$ & 1.033 & 1.017 & 1.032 & 1.018 & 1.023 & 1.026 & 1.011 & 1.075 & 1.024 & 1.033 \\
$0.5-0.6$ & 1.032 & 1.013 & 1.021 & 1.013 & 1.026 & 1.024 & 1.014 & 1.080 & 1.018 & 1.037 \\
Average & 1.044 & 1.009 & 1.035 & 1.011 & 1.026 & 1.020 & 1.014 & 1.080 & 1.021 & 1.042 \\
\hline
\end{tabular}

It can be seen from Fig.5(a), as the EP increases, the compressive strength of the three types of aggregate resinbased permeable bricks gradually increases. As shown in Fig.5(b), as the EP increases, the water permeability coefficient gradually decreases, and its trend is exactly opposite to the change trend of strength. From the mechanism analysis, with the increase of the epoxy resin content, the surface of the aggregate can be fully wetted by the epoxy resin, the resin layer between the aggregates becomes thicker and some pores are filled, the bonding area and the number of contact points Increase, the overall porosity of the resin-based permeable brick decreases, the original connected pores will gradually decrease and become unconnected, the compressive strength increases but the permeability coefficient decreases accordingly ${ }^{[13]}$.

The influence of EP on the water filtration performance of resin-based permeable bricks is shown in Fig.6.

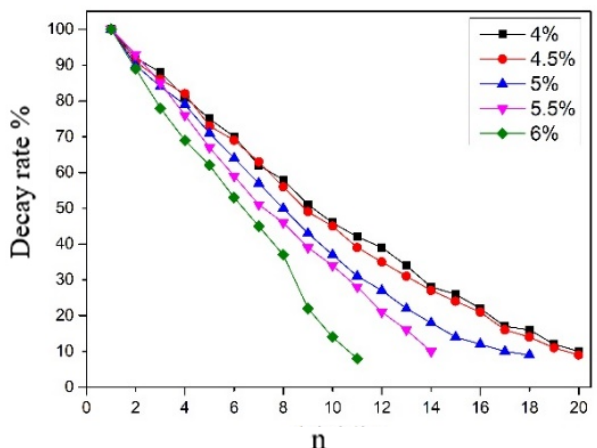

Sample (A)

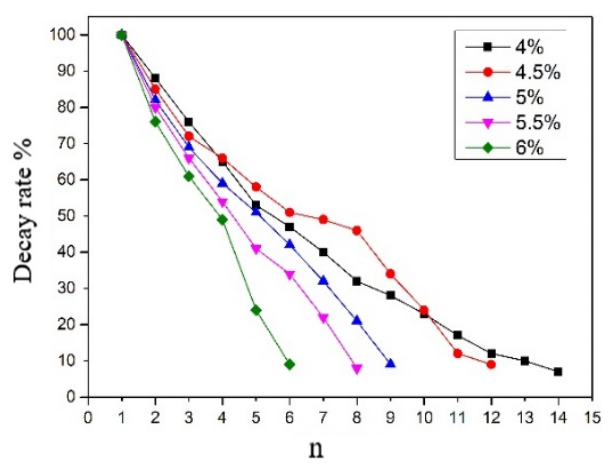

Sample (B)

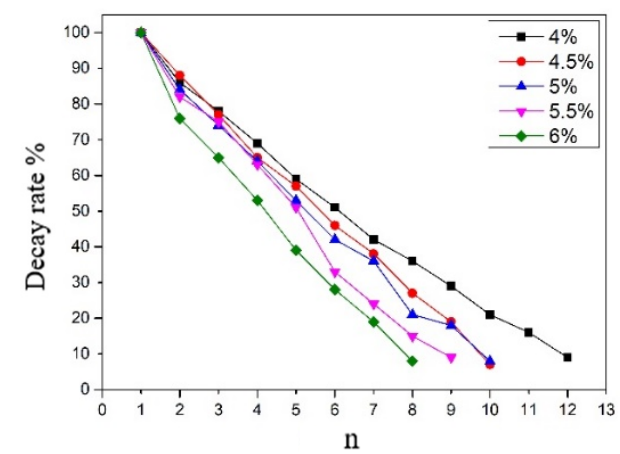

Sample (C)

Fig.6 Effect of EP on the water filtration performance of resinbased permeable bricks

It can be seen from the Fig. 6 that the change trend of the water permeability coefficient is similar. The number of water filtration decreases with the increase of the epoxy resin content, and the higher the resin content is, the faster the water permeability declines. This is because when the epoxy resin is added in a large amount, the size and number of the permeable pores are reduced, and it is easily blocked by smaller impurities, the attenuation of the permeable performance is accelerated, and the number of times of water filtration is reduced.

\subsection{Relationship between porosity, aggregate particle group parameters, resin dosage and properties of resin-based permeable bricks}

\subsubsection{Effect of different aggregates on porosity of resin-based permeable brick}

Using ten kinds of aggregates (S1-S10), a set of resin-based permeable bricks with an epoxy resin content of $5.0 \%$ were prepared, and the porosity $(\mathrm{K})$ of each set of test blocks was calculated according to formula (1) And take the average for analysis.

The characteristic parameters of the three particle groups are now integrated as a single parameter for discussion. According to the aforementioned research, the value of $\alpha$ has a positive correlation with $R$, and has a negative correlation with $\mathrm{V}$ and $\mathrm{n}$; while the $\mathrm{R}_{\mathrm{D}}$ and $\mathrm{R}_{\mathrm{G}}$ 
have a negative correlation with $\mathrm{R}$, which has a positive correlation with $\mathrm{V}$ and $\mathrm{n}$. Thus, a parameter $\mathrm{Q}$ describing the aggregate morphology level is defined, which is used to indicate the degree of influence of any aggregate particle group parameter on the performance of the resin-based permeable brick.

$$
\mathrm{Q}=\frac{\alpha}{R_{D} \cdot R_{G}}
$$

According to the influence trend of the three aggregate parameters on the performance of resin-based permeable bricks, it can be seen that the larger the $\mathrm{Q}$ of the aggregate, the more the resin-based permeable bricks tend to have a higher strength; the worse the permeable performance and filtering performance of resin-based bricks. Table 7 illustrates the original data of the particle group characteristic parameters, $\mathrm{Q}$ and $\mathrm{K}$ of the 10 kinds of aggregates. The relationship between the $\mathrm{Q}$ and $\mathrm{K}$ of the test block is shown in Fig.7.

Table 7 Characteristic parameters and Q value of 10 types of aggregates, and $\mathrm{K}$ value of test block

\begin{tabular}{|c|c|c|c|c|c|}
\hline \multicolumn{4}{|c|}{ Characteristic Parameters } & \multirow[t]{2}{*}{ Q } & \multirow[t]{2}{*}{$\mathrm{K} / \%$} \\
\hline Number & $\alpha$ & $\mathrm{R}_{\mathrm{D}}$ & $\mathrm{R}_{\mathrm{G}}$ & & \\
\hline $\mathrm{S}_{1}$ & 0.2640 & 0.887 & 1.044 & 0.272 & 18.72 \\
\hline $\mathrm{S}_{2}$ & 0.2736 & 0.945 & 1.009 & 0.416 & 19.34 \\
\hline $\mathrm{S}_{3}$ & 0.8001 & 0.907 & 1.035 & 0.693 & 16.66 \\
\hline $\mathrm{S}_{4}$ & 0.5668 & 0.928 & 1.011 & 0.595 & 15.27 \\
\hline $\mathrm{S}_{5}$ & 0.7907 & 0.898 & 1.026 & 0.885 & 5.52 \\
\hline $\mathrm{S}_{6}$ & 0.7174 & 0.889 & 1.02 & 0.791 & 7.81 \\
\hline $\mathrm{S}_{7}$ & 1.1753 & 0.895 & 1.014 & 1.087 & 3.92 \\
\hline $\mathrm{S}_{8}$ & 0.1386 & 0.878 & 1.08 & 0.134 & 28.35 \\
\hline $\mathrm{S}_{9}$ & 0.2438 & 0.91 & 1.021 & 0.225 & 29.48 \\
\hline $\mathrm{S}_{10}$ & 0.2276 & 0.902 & 1.042 & 0.246 & 24.91 \\
\hline
\end{tabular}

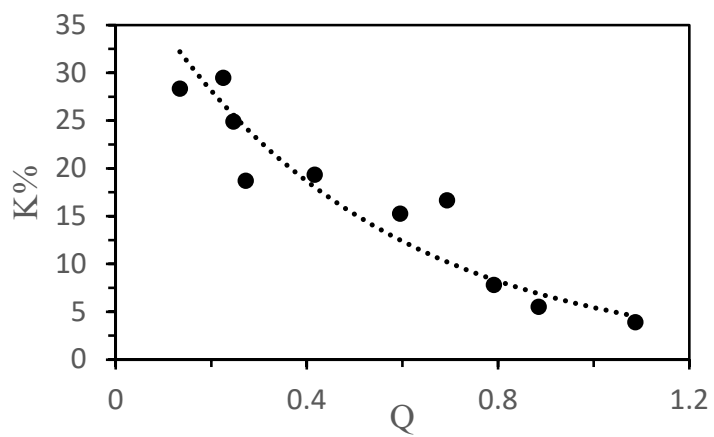

Fig. 7 Relationship between $\mathrm{Q}$ and $\mathrm{K}$

It can be seen from Fig.7, as the Q increases, the porosity of the test block gradually decreases. From the perspective of microscopic mechanism, for permeable bricks, at a certain amount of resin, the larger the $\alpha$ is, the greater the packing density and the smaller the pores formed, so the smaller the porosity shows. The lower the $R_{D}$ of the aggregate particles is, the finer the pores generated after curing and molding shows, that is, the greater the $R_{D}$ is, the greater the porosity shows; and the greater the $\mathrm{R}_{\mathrm{G}}$ of the aggregate is, the greater the degree of unevenness of the surface shows. When molding with the same amount of resin, the larger the amount of resin consumed on the surface of the aggregate and the smaller the amount of resin between the voids, the greater the porosity, that is, the greater the $\mathrm{R}_{\mathrm{G}}$, the greater the porosity. In summary, the larger the $\mathrm{Q}$ is, the smaller the porosity of the resin-based permeable brick shows.

\subsubsection{Effect of different epoxy resin dosage on porosity of resin-based permeable brick}

The value of EP discussed in this article ranges from $\quad 4.0 \%$ to $6.0 \%$. Aggregate $\mathrm{S} 4$ with a moderate $\mathrm{Q}$ value and epoxy resin with dosage of $4.0 \%, 4.5 \%, 5.0 \%, 5.5 \%$ and $6.0 \%$ were used to prepare resin-based permeable bricks, and the porosity was measured. The relationship between the porosity and the epoxy resin EP is shown in Fig.8.

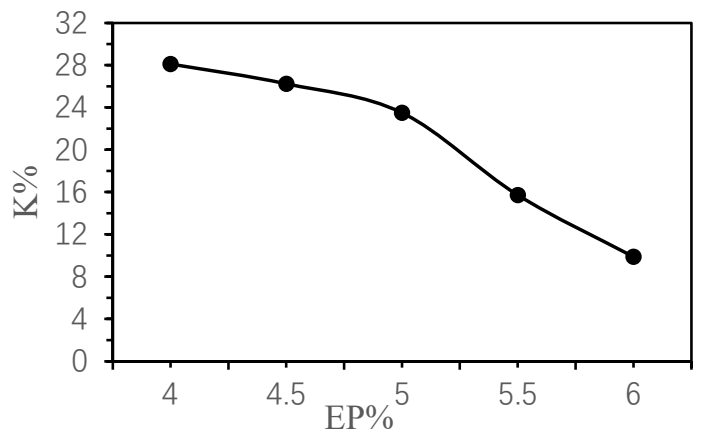

Fig.8 Relationship between EP and K

It can be seen from Fig. 8, as the EP increases, the porosity of the test block decreases. This is because, with the increasing amount of epoxy resin, the surface of the aggregate particles is gradually coated or even partially filled with resin, resulting in a decrease in the porosity. Throughout the process, the trend is to gradually reduce the porosity of resin-based permeable bricks.

\subsubsection{Analysis of the relationship between the porosity of resin-based permeable brick and its macroscopic properties}

By measuring $\mathrm{K}, \mathrm{R}, \mathrm{V}$ and $\mathrm{n}$, the relationship between the porosity of the resin-based permeable brick and three macroscopic properties was discussed. Ten kinds of aggregates (S1-S10) were used to prepare resin-based permeable brick test blocks under the formulations of epoxy resin with EP values of $4.0 \%, 4.5 \%, 5.0 \%, 5.5 \%$ and $6.0 \%$ for porosity testing and its macroscopic performance. For some samples of resin-based permeable bricks whose macro performance does not meet the standard, remain the samples whose $R \geqslant 20 \mathrm{MPa}, \mathrm{V} \geqslant 0.025 \mathrm{~cm} / \mathrm{s}$, and $\mathrm{n} \geqslant 8$.

Fig.9 shows the results that as the porosity of the sample increases, its $\mathrm{R}$ shows a general trend of decline, while $\mathrm{V}$ and the $\mathrm{n}$ show an upward trend. The greater the porosity of the material is, the smaller its packing density shows, the smaller the $\mathrm{R}$ is, the larger the diameter of the permeable channel pores shows, the more favorable for the 
permeable performance, and the same for the curing of epoxy resin, the greater the porosity, the less of solidified contact points is , the better of the water penetration performance shows and less of the strength exists ${ }^{[14]}$. .

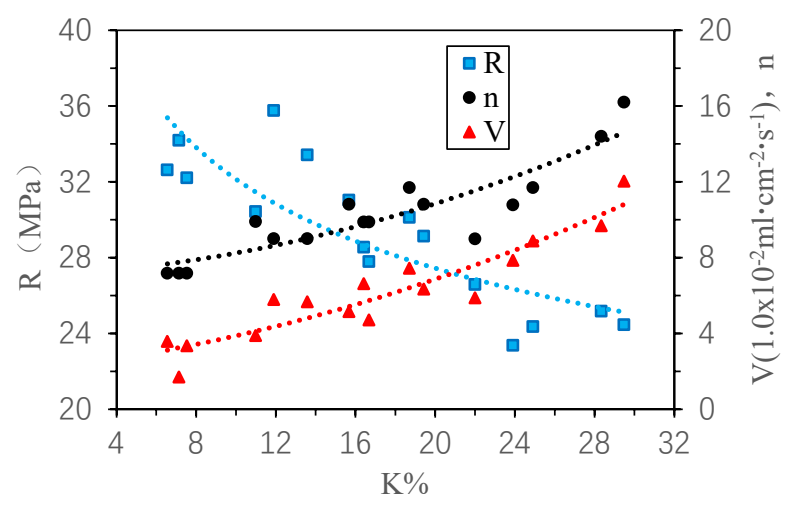

Fig.9 Relationship between $\mathrm{K}$ and macro performance

For resin-based permeable bricks, the porosity of material samples whose performance meets industry standards ranges from $6 \%$ to $30 \%$. Whose $\mathrm{R} \geqslant 30 \mathrm{Mpa}$ is divided into high-strength resin-based permeable bricks, and its porosity is in the range of $6.00 \%-15.74 \%$. Whose $\mathrm{V}$ $\geqslant 0.08 \mathrm{ml} \cdot \mathrm{cm}^{-2} \cdot \mathrm{s}^{-1}$ is divided into high permeability resinbased permeable bricks ${ }^{[9,10]}$, and its porosity ranges from $23.96 \%$ to $30.00 \%$. When the porosity of the brick is in the range of $15.74 \%-23.96 \%$, it belongs to the comprehensive performance bricks.

\subsection{Compatibility optimization of resin-based permeable pavement bricks}

Based on the above conclusions, taking the $\mathrm{Q}$ as the $\mathrm{x}$-axis, the EP as the $y$-axis, and the compressive strength of the resin-based permeable brick as the $\mathrm{z}$-axis, the relationship of strength with Q and EP is shown in Fig.10.
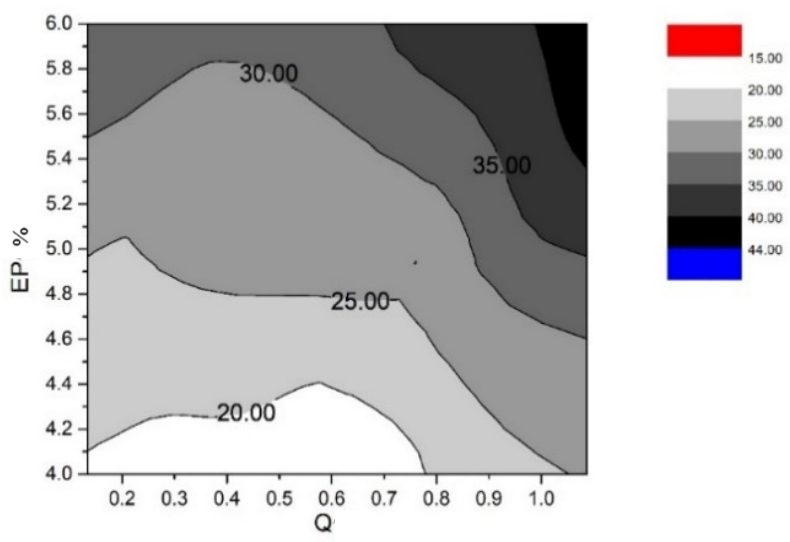

Fig.10 Relationship between Q, EP and R

From Fig.10, it can be seen that as the color of each area changes from white to gray to black, the $\mathrm{R}$ is getting larger. Among them, the white area represents the range of
$\mathrm{R}<20 \mathrm{MPa}$, which cannot meet the minimum standards of the construction industry and is unusable ${ }^{[9,10]}$.

Similarly, Fig. 11 is a two-dimensional grayscale graph of $\mathrm{V}$ (a) and $\mathrm{n}(\mathrm{b})$ of the resin-based permeable brick.
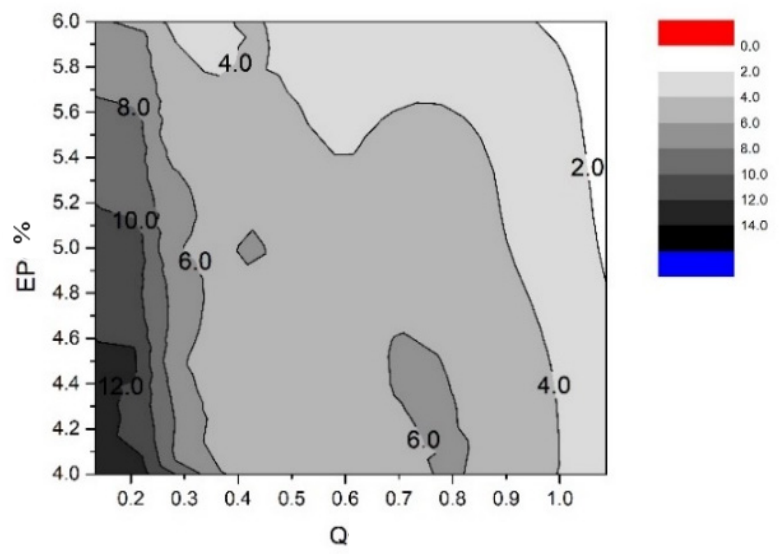

(a)
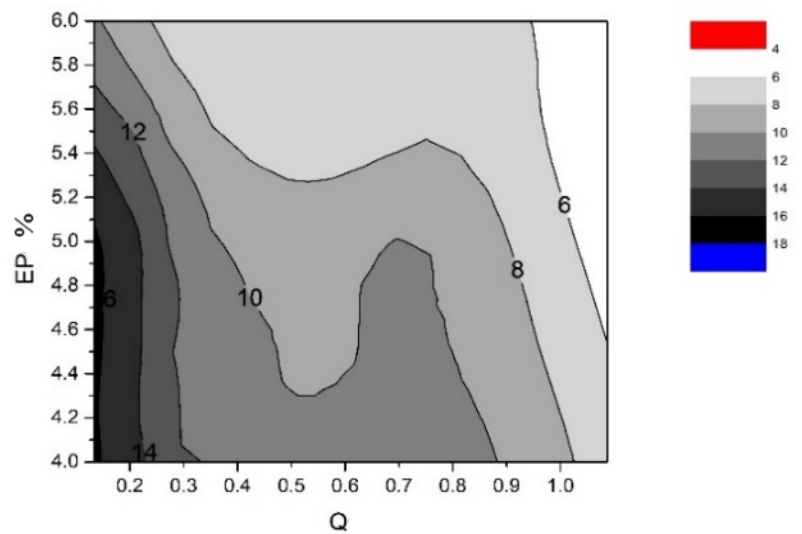

(b)

Fig.11 Relationship between Q,EP and V (a) or n (b)

The comparison shows that the change trend of Q and $\mathrm{n}$ are basically the same. As the color of each area changes from white to gray to black, the permeability and water filtration performance are getting higher and higher. Among them, the white area in Fig.11 (a) and the range below the contour line 8 in Fig.11 (b) are areas that do not meet the requirements and are unusable.

In summary, for resin-based permeable bricks, there is a certain degree of contradictory relationship between the compressive strength and the performance of water permeation and water filtration. Therefore, in the selection process of resin-based permeable bricks, its aggregate $Q$ value and epoxy resin content EP value are not desirable to one end, and its usable range is where the two overlap.

Based on the above analysis, the relationship between the three macroscopic properties and the two parameters is obtained in Fig. 12. The gray-scale distribution of the green, blue and red colors in the figure represents the relationship between Q, EP, R, V and n. Using green, red, and blue lines to indicate the limits of $\mathrm{R}, \mathrm{V}$, and $\mathrm{n}$. So the range of available resin-based permeable bricks can be visually observed from the figure. 


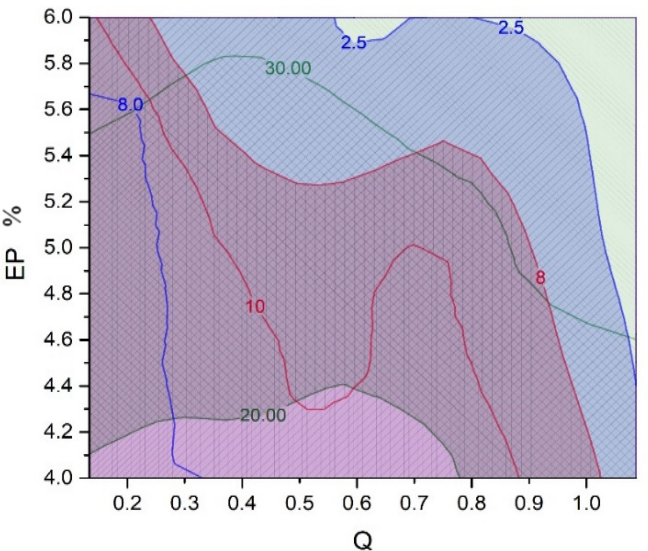

Fig.12 Model of coordination relationship of resin-based permeable brick system

The area can be divided into zone I of high-strength, zone II with excellent performance in both aspects, zone III of high permeability and zone IV with general performance but meeting industry standards. The compatibility optimization of resin-based permeable pavement bricks is shown in Fig.13.

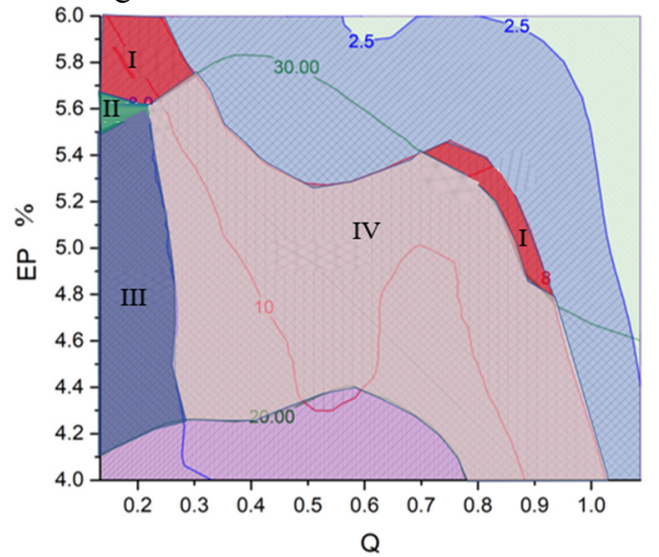

Fig.13 Compatibility optimization of resin-based permeable pavement bricks

Actually, the model can be used to predict the compressive strength, water permeability coefficient and water filtration performance of resin-based permeable pavement bricks according to the characteristic parameters and the epoxy resin dosage. In addition, raw materials can be optimal selected according to the application requirements.

\section{Conclusion}

(1) Under the same type and amount of epoxy resin, the smaller the relative standard deviation is, the greater the $R_{D}$ exists, the greater the $\mathrm{R}_{\mathrm{G}}$ shows, the better the water permeability coefficient and water filtration shows, but the compressive strength is lower.

(2) With the increase of epoxy resin content, the permeable brick's compressive strength increases, while the water permeability and water filtration performance decreases.
(3) Within a certain range, the smaller the $\alpha$ is, the greater the $R_{D}$ shows, the greater the $R_{G}$ exists, the smaller the amount of epoxy resin, the greater the porosity of the permeable brick, resulting in a decrease in the compressive strength of the permeable brick, and an increase in the permeability and water filtration performance; Thereby, an effective compatibility optimization of resin-based permeable pavement bricks is obtained.

\section{References}

1. Yong L, Tian L, Peng H. A new structure of permeable pavement for mitigating urban heat island[J]. Science of the Total Environment, 2018, 634:1119-1125.

2. Chaoqun Zhou. Production of eco-friendly permeable brick from debris $[\mathrm{J}]$. Construction and Building Materials,2018,188.

3. Wang Ping, Li Guochang. Study on the preparation and properties of sand permeable bricks in desert [J]. Nonmetallic Mine, 2010, 33 (5): 61-63.

4. Wang Pingping. Preparation and properties of resin sand-based permeable brick [D]. Dalian University of Technology, 2013.

5. Zhang Weimin, Li Lihong, Zhu Yonggang, Wang Fang, Qin Chuan, Chen Jing. Research on sand-based permeable materials [J]. Thermosetting resin, 2012, 27(06): 57-60.

6. R. Zhong,K. Wille. Linking pore system characteristics to the compressive behavior of pervious concrete $[\mathrm{J}]$. Cement and Concrete Composites,2016, 130-138.

7. ALTUHAFI F,O SULLIVAN C,CAVARRETTA I. Analysis of an image-based method to quantify the size and shape of sand particles[J]. Journal of Geotechnical and Geoenvironmental Engineering, 2013, 139 (8): 1290-1307.

8. MORA C F,KWAN A K H. Sphericity,shape factor and convexity measurement of coarse aggregate for concrete using digital image processing $[\mathrm{J}]$. Cement and Concrete Research,2000,30(3):351-358.

9. GB/T 25993-2010, Permeable pavement tiles and permeable pavement panels[S].

10. JG/T 376-2012, Sand-based permeable brick [S]

11. Jiang Zhengwu, Sun Zhenping, Wang Peiming. Influence of several factors on the properties of porous permeable concrete [J]. Journal of Building Materials, 2005,8 (5): 513-519.

12. Li Xiaoyan, Bu Yin, Wang Hainian et al. Research on quantitative evaluation index of morphological characteristics of coarse aggregates [J]. Journal of Building Materials, 2015,18 (3): 524-529.

13. Zhang Xiong,Wang Xiaofu.Research progress on the influence mechanism of several factors on the performance of permeable brick[J].Materials Review:1-20,2019.

14. Wang Zhongjia, Yang Ce, Weng Daqing, Zheng Zhijie, Meng Tao, Hong Yongpeng. Study on the effect of target porosity on the performance of recycled permeable bricks[J].New Building Materials,2019,46(04):51-54. 